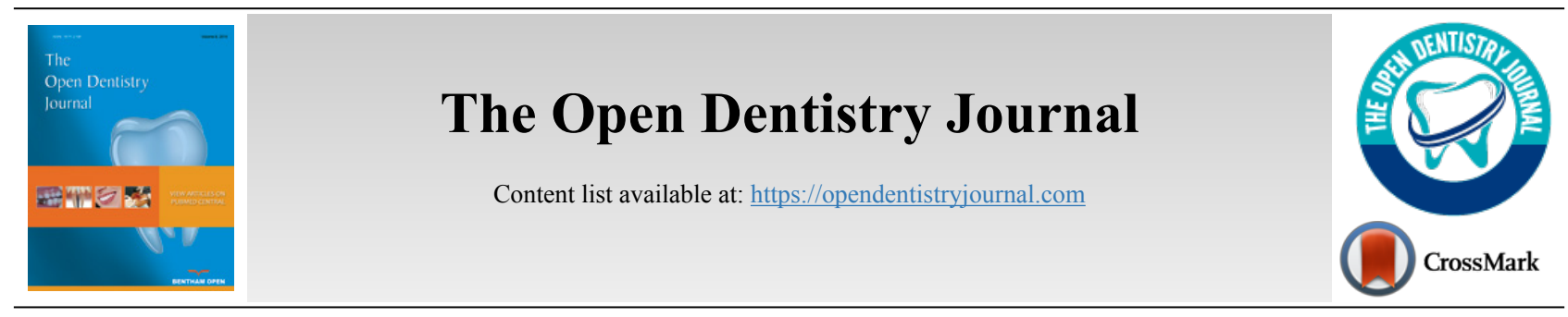

RESEARCH ARTICLE

\title{
Dentition Status and Treatment Needs Among Orphans in Riyadh City, Saudi Arabia: A Cross-sectional Descriptive Study
}

Abdulrahman Alsayeh ${ }^{1, *}$, Mohammed Abdulbaseer ${ }^{1}$, Heyam Aljelaly ${ }^{1}$, Bader Alshamrani ${ }^{1}$, Reem Aldaijy ${ }^{1}$, Khalid Alshlash $^{1}$, Tala Odeh ${ }^{1}$ and Abdulrahman Alshiha ${ }^{1}$

${ }^{1}$ Department of Dentistry, Riyadh Elm University, Qurtubah, Riyadh 13244, Saudi Arabia

\begin{abstract}
:
Background:

Oral health affects the general health and quality of life of an individual. It has been well documented that the absence of family support influences the general and oral health of children. Factors that lead to the development of a disease are likely to have their roots in a complex chain of environmental events that may have begun years before the disease occurs. The purpose of this study was to examine the prevalence of dental caries and assess treatment needs of the orphans of Riyadh City, Saudi Arabia
\end{abstract}

Methods:

This cross-sectional study included 238 orphaned children aged 6 to 18 years. Clinical examination was conducted by two doctors, and oral findings were recorded according to the World Health Organization (WHO) oral health assessment form (1997). The data collected was analyzed using SPSS 21.0.

Results:

Results revealed that $37 \%$ of the participants reported that they do not brush their teeth, $23 \%$ of the participants reported that they do not brush regularly, $17 \%$ of the participants reported that they brush one time daily, and $23 \%$ of the participants reported that they brush twice daily. The prevalence of dental caries among the participants was $96.6 \%$. When examining treatment needs among study participants, $7.6 \%$ might need preventive caries arresting care, $49.6 \%$ might need fissure sealant applications, $51.3 \%$ might need at least one surface filling, $13.1 \%$ might need two or more surface filling, $2.5 \%$ might need crown for any reason, $0.4 \%$ of participants might need veneer or laminate, $0.2 \%$ of participants might need pulp care and restoration, and $8.1 \%$ might need extraction.

Conclusion:

Results of our study indicate that orphan children have low utilization of preventive and therapeutic oral health services. Urgent attention is required to plan a comprehensive dental health-care program to improve their oral health status.

Keywords: Oral health, Dentition status, Orphan, Children, Reatment needs, Salvadora persica.

\begin{tabular}{l|l|l|l} 
Article History & Received: December 29, 2019 & Revised: March 08, 2020 & Accepted: March 12, 2020
\end{tabular}

\section{INTRODUCTION}

Parents are the primary caretakers of a child. They take care of their children by protecting them from hazards and teach them honesty, courtesy, respect, generosity, and love. Unfortunately, there are many children underprivileged from their parents' care either one of them or both of them. The United Nations International Children's Fund and global part-

\footnotetext{
* Address correspondence to this author at the Department of Dentistry, Riyadh Elm University, Qurtubah, 13244, Riyadh, Saudi Arabia; Tel: +1313-550-5986; E-mail: Alsayeh94@gmail.com
}

ners define an orphan as a child under 18 years of age who has lost one or both parents for any cause of death. By this definition, due to wars, natural disasters, infections, and other causes, there are nearly 140 million orphans living in the world today $[1,2]$. According to the Ministry of Labor and Social Development in Saudi Arabia, in 2015, there were 1145 orphans in Riyadh, a region of Saudi Arabia [3].

Oral health is an important contributor to overall health and well-being $[4,5]$. According to the new definition of oral health that was announced by the World Dental Federation, and over 200 national dental organizations, includingthe American 
Dental Association, "The oral health is multi-faceted and includes the ability to speak, smile, smell, taste, touch, chew, swallow and convey a range of emotions through facial expressions with confidence and without pain, discomfort, or disease of the craniofacial complex [6,7]. A gloobal review of oral health showed that $90 \%$ of schoolchildren worldwide experienced caries $[8,9]$.

The level of oral diseases in the community is influenced by the environment, individual's lifestyles, behaviors, and socioeconomic factors [10]. Despite improvements in oral health with newer technology and materials, the global problem persists. Oral disease is particularly more prevalent among underprivileged groups, and orphans are considered a high-risk group [11, 12]. According to the Social Affairs Ministry of Saudi Arabia, there are 12,000 orphans among a population of 28 million [3]. The orphans represent $3 \%$ of the total population of children in Saudi Arabia. Although orphans contribute to $2 \%$ of the world's population, studies regarding their oral health status are scarce. To the fullest of our knowledge, there has been no previous study addressing the issue of oral health of orphans in Riyadh, Saudi Arabia. This study aimed to assess the prevalence of dental caries in orphaned children in Riyadh, Saudi Arabia. Our study will provide insight regarding dental health in orphans, which is a significant issue, so that the government and the private sector can be aware of this issue and so that programs addressing this issue can be developed.

\section{MATERIALS AND METHODS}

A descriptive cross-sectional study was conducted to assess the prevalence of dental caries and to assess the treatment need among orphans in Riyadh, Saudi Arabia. This study was approved by the ethical committee of Riyadh Elm University (IRB approval: FIRP/2018/156).Approval was taken from Insan Orphanages center (Fig. 1). By considering the prevalence rate of dental caries to be $90 \%$, the sample size required was 238 at $95 \%$ confidence level and $5 \%$ confidence interval. Participants were randomly selected and a total of 238 orphans were included, divided as 177 (74\%) male orphans and $61(26 \%)$ female orphans. We included orphans aged 6 to 18 years and orphans who were willing to participate and cooperate.

\section{Data collection form}

\begin{tabular}{|c|c|c|c|}
\hline \multicolumn{4}{|l|}{ Age: } \\
\hline Gender: & 1. Male & \multicolumn{2}{|c|}{ 2. Female } \\
\hline Nationality: & 1. Saudi & \multicolumn{2}{|c|}{ 2. Non-Saudi } \\
\hline \multicolumn{4}{|c|}{ Number of siblings: .............. } \\
\hline \multirow{5}{*}{\multicolumn{3}{|c|}{ How many times you brush your teeth: }} & 1. Once daily \\
\hline & & & 2. Twice daily \\
\hline & & & 3. Three times daily \\
\hline & & & 4. Once weekly \\
\hline & & & 5. I don't brush \\
\hline \multirow{4}{*}{\multicolumn{3}{|c|}{ At what time do you brush your teeth: }} & 1. Morning only \\
\hline & & & 2. Evening only \\
\hline & & & $\begin{array}{l}\text { 3. Once morning and once in the evening } \\
\text { before going to bed. }\end{array}$ \\
\hline & & & 4. I don't brush \\
\hline \multirow{4}{*}{\multicolumn{3}{|c|}{ What do you use for cleaning your teeth: }} & 1. Tooth brush and toothpaste \\
\hline & & & 2. Miswak \\
\hline & & & 3. Finger with paste \\
\hline & & & 4. I don't brush \\
\hline \multirow{4}{*}{\multicolumn{3}{|c|}{ What method you use to clean teeth }} & 1. Horizontal \\
\hline & & & 2. Vertical \\
\hline & & & 3. Scrub \\
\hline & & & 4. I don't brush \\
\hline \multicolumn{4}{|c|}{ When was your last visit to dentist? } \\
\hline
\end{tabular}

Fig. (1). Questionnaire that distributed to the orphans. 
There were three interns. The interns were trained by the principal researcher to fill the form that was the World Health Organization oral health assessment form (1997) [13,14]. A clinical examination was conducted on all 238 participants. All examinations were carried out in a well-lit room. Instruments used in examinations weredisposable dental examination kit,which consisted of a dental examination mirror Kerr model PE9401, Anhui, China, double-ended probe (examination/perio WHO-type 3.5, 5.5, 8.5 \& $11.5 \mathrm{~mm}$ ) Kerr model PE9401, Anhui, China, tweezers Kerr model PE9401, Anhui, China, masks Kerr model PE9401, Anhui, China, bib Kerr model PE9401, Anhui, China, tissue wipe Kerr model PE9401, Anhui, China, cotton rolls Kerr model PE9401, Anhui, China, and a biodegradable tray Kerr model PE9401, Anhui, China, with disposable gloves, Sanita, Riyadh, Saudi Arabia. A structured questionnaire that was originally written in English was translated in Arabic and distributed in both English and Arabic (Fig. 2). The respondents were asked questions on basic knowledge, such as frequency of brushing, technique of brushing, and methods and aid used for cleaning oral cavity. We added a question about the use of miswak as a method for taking care of oral health. Miswak is a traditional chewing stick prepared from the roots, twigs, or stem of Salvadora persica tree and has been used in the country as a natural method for tooth cleaning. A number of scientific studies have demonstrated that miswak (Salvadora persica) possesses antibacterial, anti-fungal, anti-viral, anti-cariogenic, and antiplaque properties [15]. The Simplified Oral Hygiene Index (OHI-S) by Greene and Vermillion [16] was used and included a debris index, calculus index, plaque index, and gingival index. Each of these indexes is based on numerical determinations representing the amount of debris or calculus found on the preselected tooth surfaces. The examination was performed by using the Disposable Examination Kit.

\subsection{Statistical Analysis}

The data were analyzed using SPSS version 21. Mean and standard deviations were calculated to express the mean Decayed Missing Filled Surface DMFS values. The chisquared test was used to assess associations between treatment needs and various risk factors including lifestyle and social support, oral hygiene practice, utilization of a toothbrush, a toothpaste, and dental floss, and frequency of visits to dentists. Specific statistical testswere used including (Spearman's rho, Mann-Whitney U) .A $\mathrm{p}<0.05$ was considered statistically significant.

\section{RESULTS}

The age range of the study participants was 6 to 18 years, with a mean age \pm standard deviation of $13.98 \pm 2.45$ years. The majority $(93.6 \%)$ of the participants were 10 years and above. The gender distribution of the study participants was 177 male participants and 61 female participants.

Results revealed that $37 \%$ of the participants reported that they do not brush their teeth, $23 \%$ of the participants reported that they do not brush regularly, $17 \%$ of the participants reported that they brush one time daily and $23 \%$ of the participants reported that they brush twice daily (Fig. 3), which indicate that the participants were highly susceptible to dental caries.

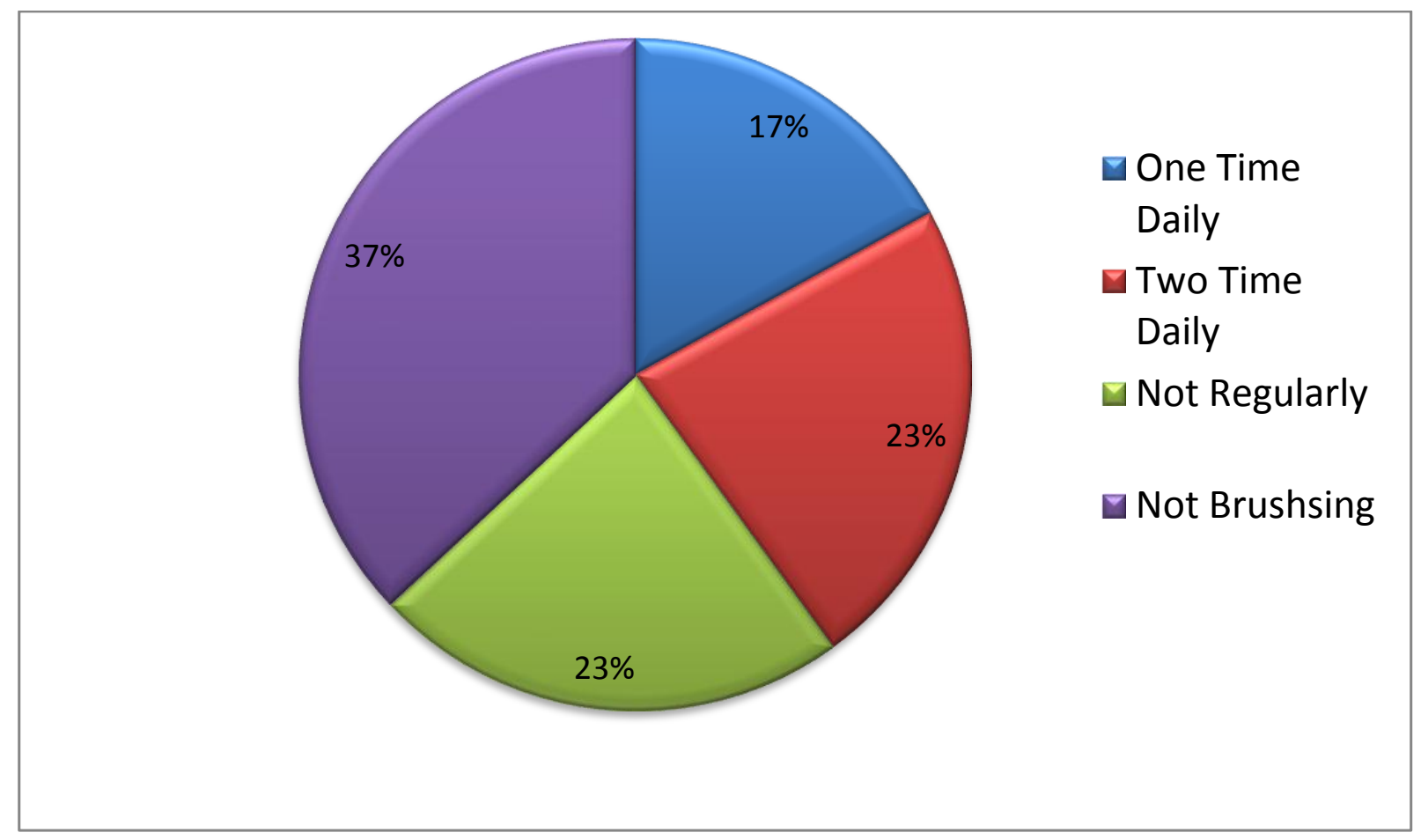

Fig. (2). Brushing habit. 


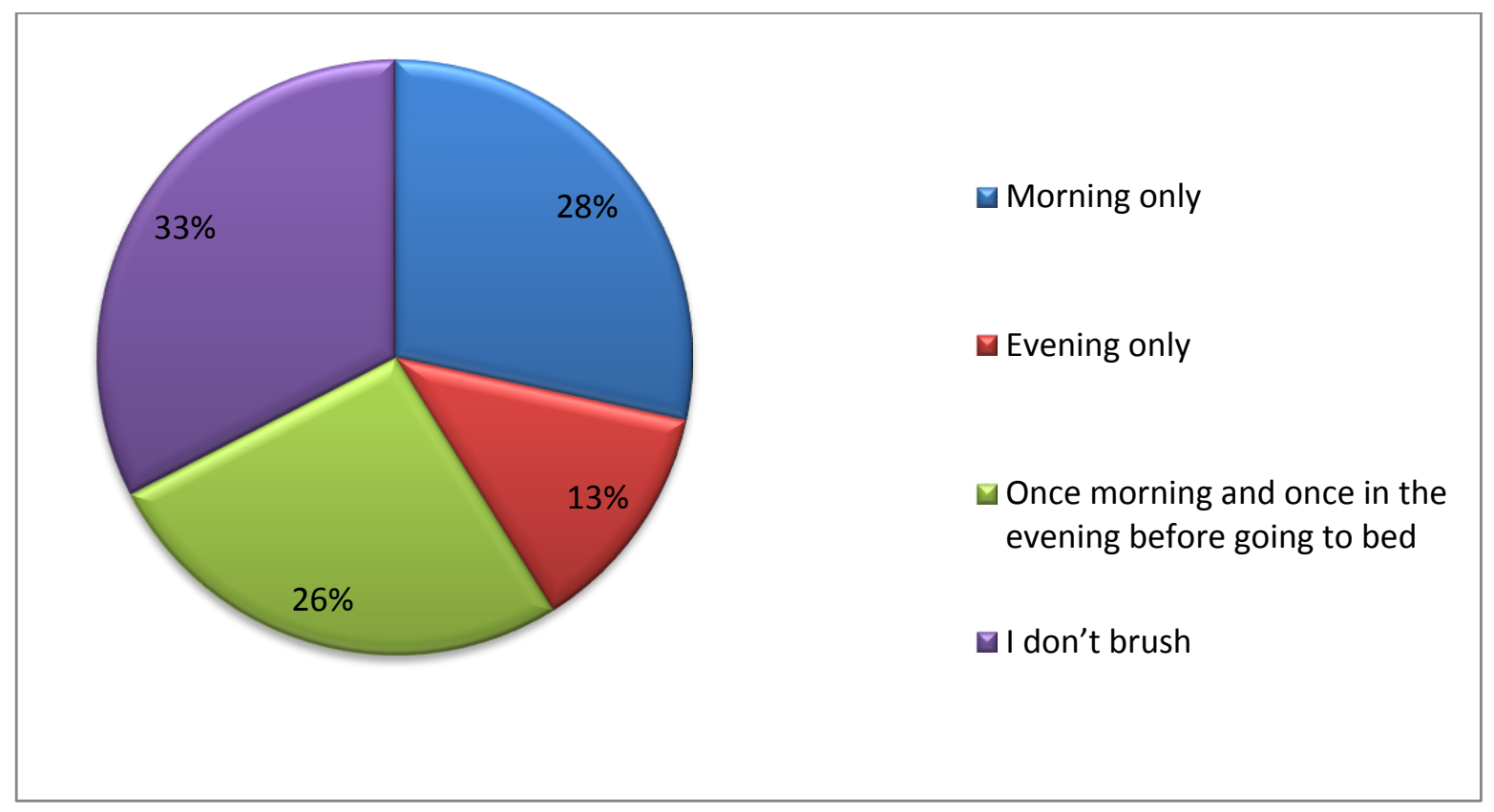

Fig. (3). Frequent of brushing.

When evaluating the time at which participants brush their teeth, $28 \%$ of the participants used to brush their teeth only at morning, $13 \%$ of the participants used to brush their teeth only at night and $26 \%$ of the participants used to brush their teeth

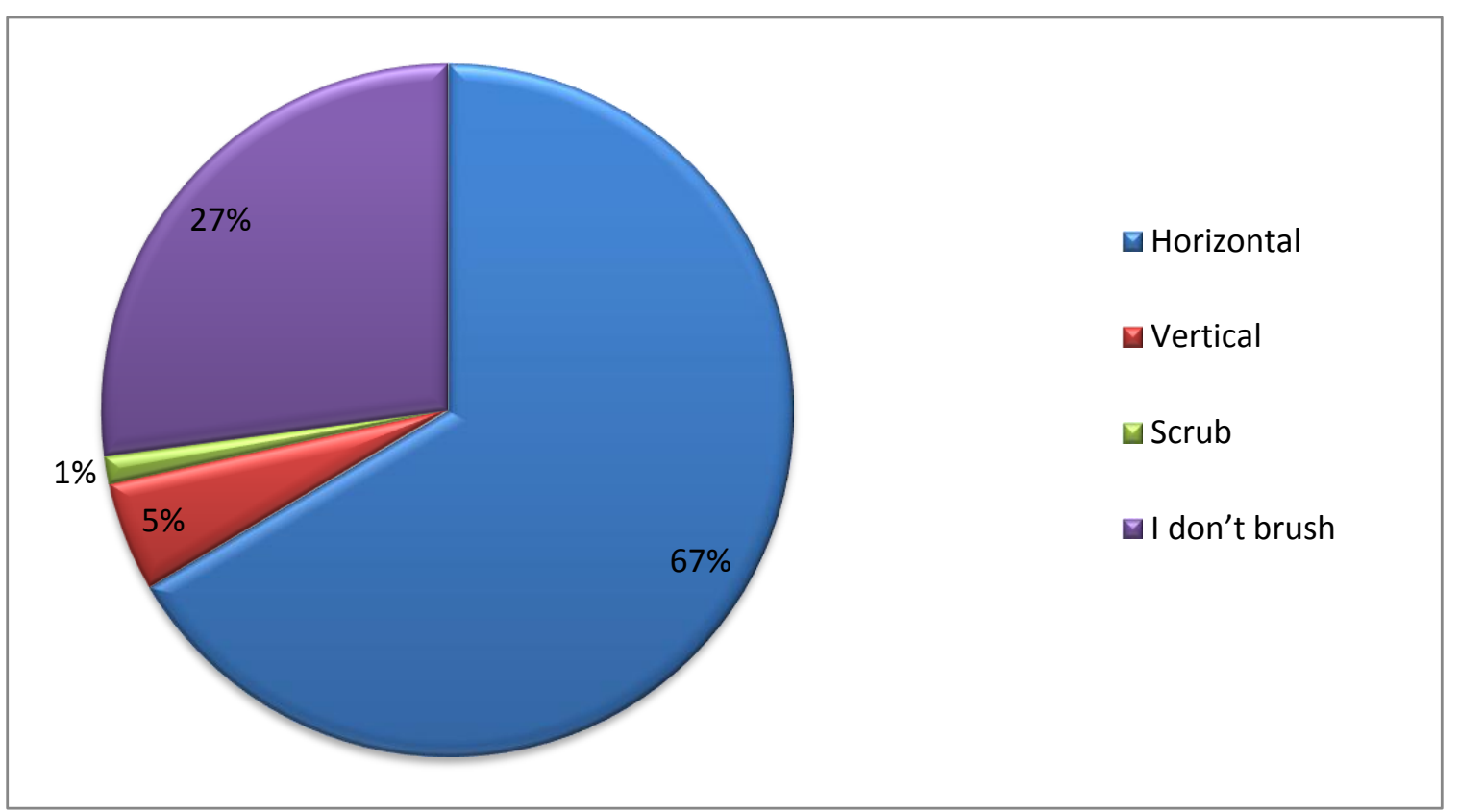

both morning and night (Fig. 4). While examining the technique of brushing, $67 \%$ of the participants would brush their teeth in the horizontal direction , $5 \%$ of the participants would brush their teeth in a vertical motion and $1 \%$ of the participants would brush their teeth in a scrub motion (Fig. 5).

Fig. (4). brushing techniques. 


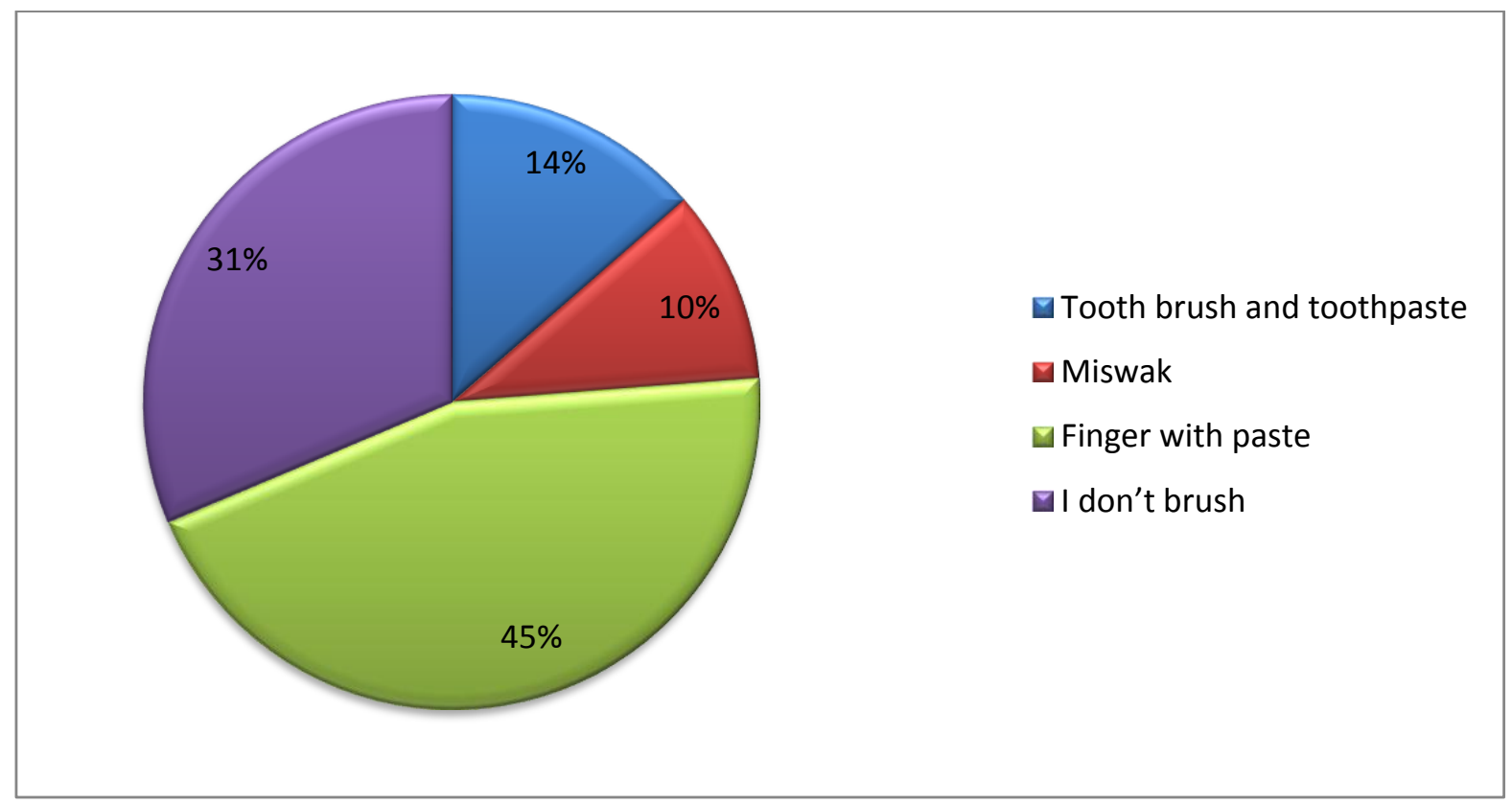

Fig. (5). Brushing tools.

While examining the tools used by orphans for brushing their teeth, $14 \%$ of the participants reported to brush their teeth using a toothpaste with a brush, $10 \%$ of the participants reported to use miswak and $45 \%$ of the participants reported to use their finger with toothpaste.

Study results show that the prevalence of dental caries among participants was $96.6 \%$ for debris index, calculus index, plaque index, and gingival index. The median score was one. The scoring criteria are listed in Table 1. Spearman's Rho showed a statistically significant positive correlation between debris index, calculus index, plaque index, and gingival index $(\mathrm{p}=0.000)$.

The mean \pm standard deviation DMFS of the participants was $8.40 \pm 4.19$ (range: $0-18$ ). The mean \pm standard deviation DMFS of female participants $(9.42 \pm 3.20)$ was higher than that of male participants $(8.04 \pm 4.44)$ (Fig. 6). Furthermore, the Mann-Whitney $U$ test showed that this difference was statistically significant $(p=0.008)$. Spearman's Rho showed a statistically significant positive correlation between DMFS and age ( $\mathrm{rho}=0.216, \mathrm{p}=0.001)$, suggesting that DMFS increased with age.

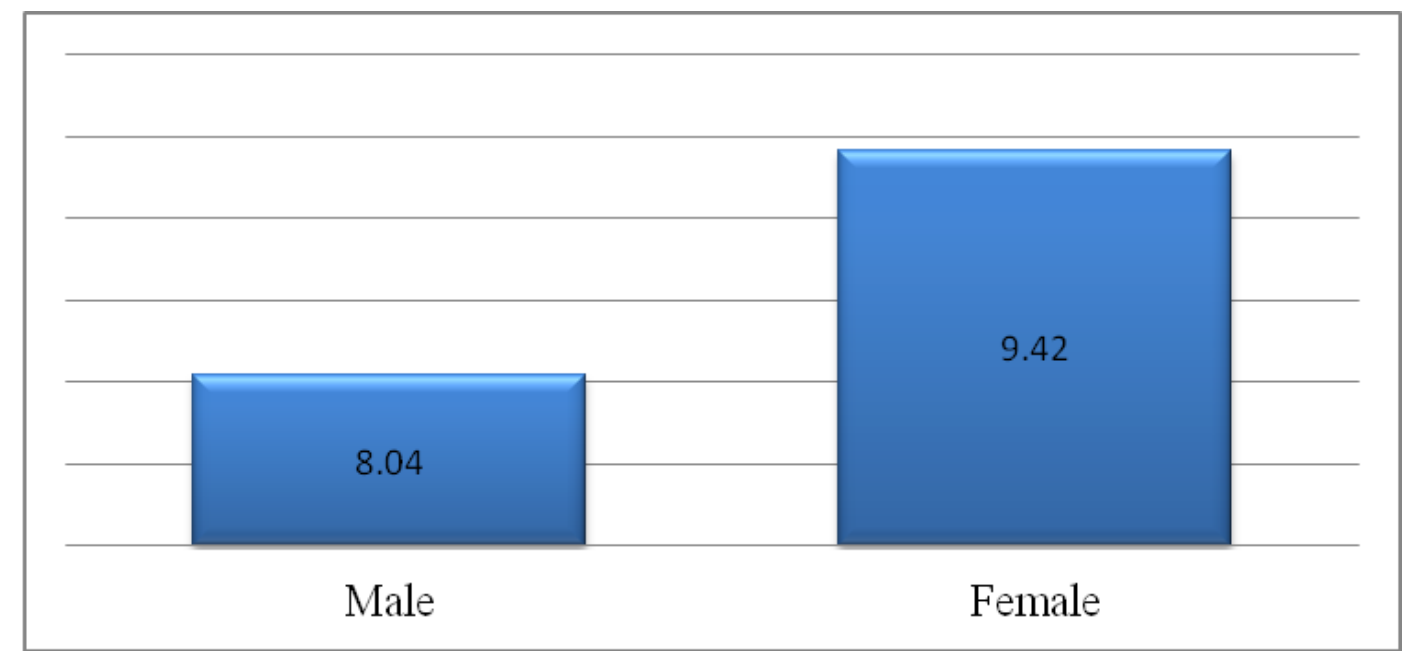

Fig. (6). DMFS of the participants. 
Table 1. Debris index (0 no debris of stain, 1 soft debris covering one third of tooth surface, 2 Soft debris covering more than one third, but not more than two thirds, of the exposed tooth surface, 3 soft debris more than two thirds of the exposed tooth surface ), Calculus index ( 0 no calculus, 1 mild calculus, 2 moderate calculus, 3 heavy calculus ), Plaque index ( 0 absence of plaque, 1thin film of plaque, 2 moderate plaque accumulation, 3 large amount of plaque ), Gingival Index (0 normal, $1 \mathrm{mild}$ inflammation, 2 moderate inflammation, 3 severe inflammation ).

\begin{tabular}{|c|c|c|}
\hline Index & Median Score & Scoring Criteria \\
\hline Debris & Score 1 & $\begin{array}{l}\text { Soft debris covering not more than } 1 / 3^{\text {rd }} \\
\text { of the exposed tooth surface or presence of extrinsic stains without other debris regardless of surface area covered }\end{array}$ \\
\hline Calculus & Score 1 & Supragingival calculus covering not more than $1 / 3^{\text {rd }}$ of the exposed tooth surface \\
\hline Plaque & Score 1 & $\begin{array}{l}\text { A film of plaque adhering to the free gingival margin and the adjacent area of the tooth. The plaque may be recognized only } \\
\text { by running a probe across the tooth surface }\end{array}$ \\
\hline Gingival & Score 1 & Mild inflammation, slight change in color \& edema, but no bleeding on probing \\
\hline
\end{tabular}

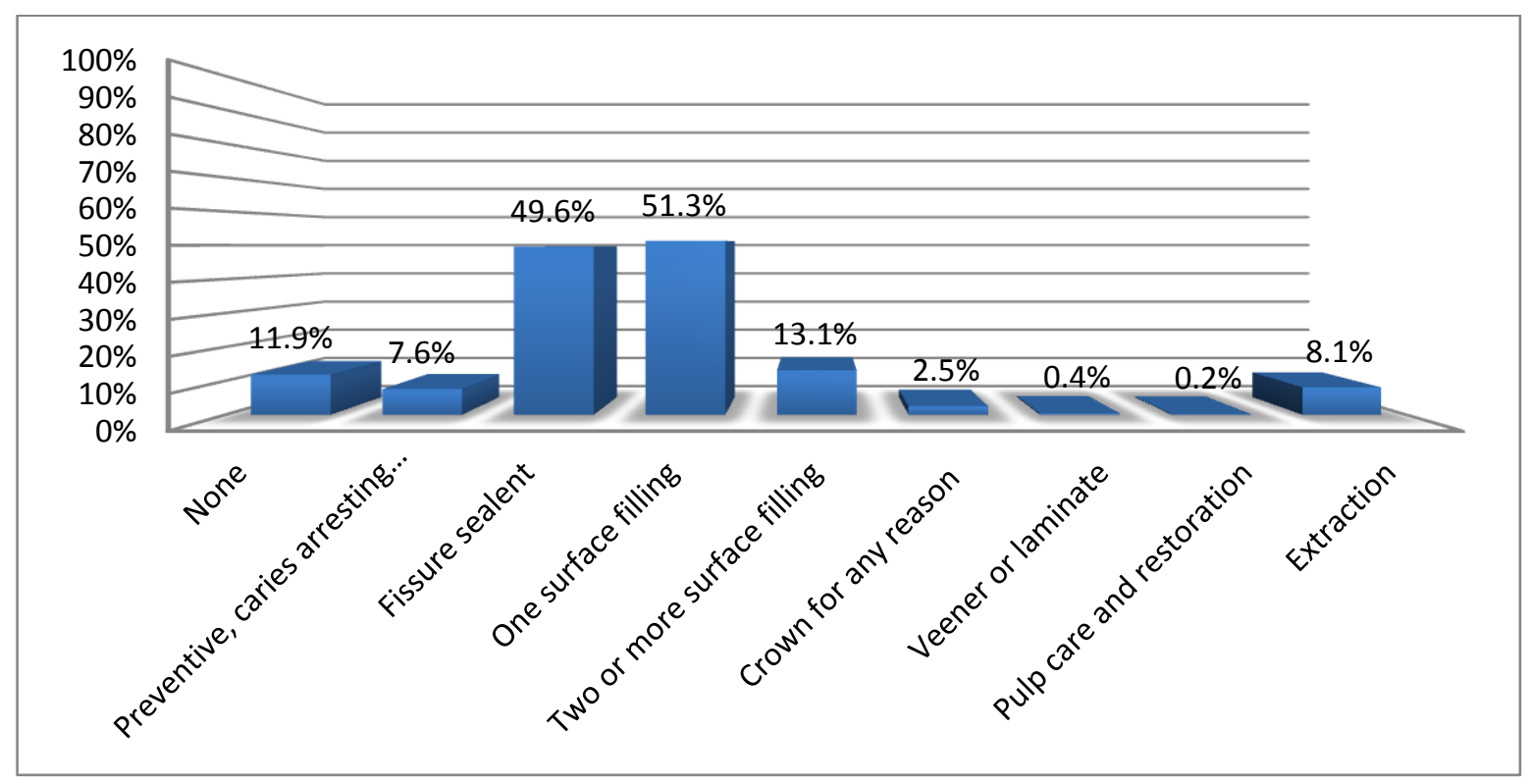

Fig. (7). Treatment needs.

When examining treatment needs among study participants, $7.6 \%$ needed preventive caries arresting care, $49.6 \%$ needed fissure sealant applications, $51.3 \%$ needed at least one surface filling, $13.1 \%$ needed two or more surface filling, $2.5 \%$ needed crown for any reason, $0.4 \%$ needed veneer or laminate, $0.2 \%$ needed pulp care and restoration and $8.1 \%$ of participants needed extraction (Fig. 7).

\section{DISCUSSION}

Nowadays,, parents face many difficulties in controlling their children from consuming candies and beverages that effect their oral health. In contrast for those whose don't have their parents with them, there is no one to make sure of children's oral health, resulting in increased consumption of candies and beverages which cause more caries as reported in a study by Caneppele TM, Jeronymo RD [17] , in their study that done on one hundred standardized dentin slabs obtained from bovine incisor roots which study effect beverage on teeth, result shows increase of erosion on roots dentin which mean more caries which show why we have high consideration about consumption of beverages, candies, sweet etc.

In Saudi Arabia, although there are many epidemiological studies on oral health in children, limited studies have examined oral health in orphan children in Saudi Arabia. The main purpose of this study was to identify the dentition status and treatment needs among orphaned children of Riyadh City, Saudi Arabia.

The present study included 238 orphans among them $93.6 \%$ were $\geq 10$ years of age.

The mean record of DMFS was $8.40 \pm 4$.19.Previously, Alsadhan [18,19] reported that the DMFS value ofmale schoolchildren aged 12-14 years was 7.20 \pm 3.89 . Our results showed that the DMFS value of male orphans was $8.04 \pm 4.44$ which is higher than the that shown in Alsadhan study which seems realistic due to loss of their parents. The caries prevalence in our study participants was $96.6 \%$, which is higher when compared to a previous study conducted by 
Aldosari [20], which reported that caries prevalence among intermediate schoolchildren was $92.3 \%$.

Regarding brushing teeth, $37 \%$ of the participants reported that they do not brush their teeth and $23 \%$ of participants reported that they do not brush their teeth regularly. This may be explained by the fact that since the participants lost their parents, they neversaw their parents brushing their teeth while the participant was of preschool age. Ozbek [21] compared the tooth brushing habit between children and their parents and the result showed significant association in the frequency of tooth brushing between the parents and their children. If their parents brushed their teeth once a day, children were more likely to brush their teeth $\geq 1$ time a day.

The majority of the participants needed preventive care followed by fissure sealant, one surface filling, two surface filling, pulp therapy, malocclusion correction, and extrac-tions. Out of 238 participants, only $3.4 \%$ showed good oral health care. These figures were compared with a study by Khare et al. [22], where $26.2 \%$ of the participants required one surface filling which was lower than our study being 51.3\%.18.3\% required two or more surface fillings which was higher than the result achieved in our study being $13.1 \% .8 .1 \%$ of the partipants in our study had teeth requiring extraction,compared to $5.2 \%$ reported in the study by Khare et al study. Finally, acidic environment that result from eating high sugar content food and drinks that mainly found in sweets, beverages, etc. can effect even restoration, study done by poggio, violo, mirando [23] focused on effect of beverage on some types of restoration, in their study they used thirty specimens of each esthetic restorative material., their results shows the effect of acidic environment on restorations (Needs to be rephrased).

\section{LIMITATION}

In our research, there are limitations; firstthe data collected for habits and practices may be limited. Secondly, there were some difficulties faced in achieving a balance between the number of male and female orphans due to refusal from some females to participate which influenced the result of the research. Third, the data on oral health knowledge, attitudes, and practices of orphan children with regard to consumption of sugary foods and drinks are very scarce. Due to this fact, and a comparison with a non-orphan population consider one of the limitation in our study, this research can used as reference in future researches.

\section{CONCLUSION}

Death or absence of one or both parents can lead to bad oral health of children. Thus, orphaned children are vulnerable and are potentially at an increased risk for poor health. This study shows that there is a great need for implementing preventive measures among orphaned children living under special circumstances. This research is the first study of its kind conducted in Saudi Arabia and there were no prior study conducted in Saudi Arabia. It has been observed that the oral health of orphans was poor and this community has low utilization of preventive or therapeutic oral health services. Prevention programs targeting dental caries such as sealant programs and fluoride programs should be started soon as possible for this population. In the future, orphans should be considered a priority group when formulating plans for oral health care.

\section{LIST OF ABBREVIATION}

\section{DMFS $=$ Decayed Missing Filled Surface}

\section{AUTHOR'S CONTRIBUTIONS}

TO and BS and AS performed the examination on the children, KA and did the research design, AA and made the structured questionnaire construction in English and translated to Arabic. RD performed the data analysis, AA and TO were major contributors in writing the manuscript. All authors read and approved on the final manuscript

\section{ETHICS APPROVAL AND CONSENT TO PARTI- CIPATE}

This study was approved by the Ethical Committee of Riyadh Elm University, Saudi Arabia (IRB appr-oval: FIRP/2018/156).

\section{HUMAN AND ANIMAL RIGHTS}

No animals were used in this study. All humans research procedures followed were in accordance with the guidelines of the Declaration of Helsinki of 1975, as revised in 2008.

\section{CONSENT FOR PUBLICATION}

Informed consent approval letter was given by Ensan, the Charity Committee for Orphans Care

\section{AVAILABILITY OF DATA AND MATERIAL}

The data that support the findings of this study are available from the corresponding author, [A.A], upon reasonable request.

\section{FUNDING}

None.

\section{CONFLICT OF INTEREST}

The authors declare no conflict of interest, financial or otherwise.

\section{ACKNOWLEDGEMENTS}

We would like to thank all the head of Ensan the Charity Committee for Orphans Care, caretakers of orphanages and all the children who participated in the study. for their cooperation.

\section{REFERENCES}

[1] United Nations International Children's Emergency Fund (UNICEF) (UNICEF): Orphans. 2019. Available from https://www.unicef.org /media/orphans

[2] SOS Children's Villages. Children's Statistics Available from: https://www.sos-usa.org /our-impact/focus-areas/advocacy-movementbuilding/childrens-statistics

[3] Ministry of labor and social development. Available from:. https://mlsd.gov.sa /en/reports2003.

[4] Baiju RM, Peter E, Varghese NO, Sivaram R. Oral Health and Quality of Life: Current Concepts. J Clin Diagn Res 2017; 11(6): ZE21-6. 
[http://dx.doi.org/10.7860/JCDR/2017/25866.10110]

[PMID: 28764312]

[5] Jin LJ, Lamster IB, Greenspan JS, Pitts NB, Scully C, Warnakulasuriya S. Global burden of oral diseases: Emerging concepts, management and interplay with systemic health. Oral Dis 2016; 22(7): 609-19.https://www.ncbi.nlm.nih.gov/pubmed/26704694 [http://dx.doi.org/10.1111/odi.12428]

[6] World Dental Federation. FDI'S definition of oral health. Available from:. Https:// www.fdiworlddental.org /oral-health/fdis-definition-oforal-health

[7] Glick M, Williams DM, Kleinman DV, Vujicic M, Watt RG, Weyant RJ. A new definition for oral health developed by the FDI World Dental Federation opens the door to a universal definition of oral health J Am Dent Assoc 2016; 147(12): 915-7.

[8] Hobdell M, Petersen PE, Clarkson J, Johnson N. Global goals for oral health 2020. Int Dent J 2003; 53(5): 285-8.

[http://dx.doi.org/10.1111/j.1875-595X.2003.tb00761.x] [PMID: 14560802]

[9] Andegiorgish AK, Weldemariam BW, Kifle MM, et al. Prevalence of dental caries and associated factors among 12 years old students in Eritrea. BMC Oral Health 2017; 17(1): 169.

[http://dx.doi.org/10.1186/s12903-017-0465-3] [PMID: 29284471]

[10] Surgeon general's report on oral health in america. National institute of dental and craniofacial research Available from: https://www.nidcr.nih.gov/research/data-statistics/surgeon-general

[11] Orphans consider as high risk . Available from: https://www.sos childrensvillages.org/getmedia/384bc38a-62aa-4c2a-9563a5ecc61b6a77/SOS-Child-at-risk-report-web.pdf

[12] Al-Meedani LA, Al-Dlaigan YH. Prevalence of dental caries and associated social risk factors among preschool children in Riyadh, Saudi Arabia. Pak J Med Sci 2016; 32(2): 452-6.

[13] Petersen PE. World Health Organization global policy for improvement of oral health--World Health Assembly 2007. Int Dent J 2008; 58(3): 115-21.

[http://dx.doi.org/10.1111/j.1875-595X.2008.tb00185.x] [PMID: 18630105]

[14] Chen MS, Andersen RM, Barmes DE. Comparing oral health care systems: A second international collaborative study. Geneva: World Health Organization 1997. [Google Scholar]
[15] Haque MM, Alsareii SA. A review of the therapeutic effects of using miswak (Salvadora Persica) on oral health. Saudi Med J 2015; 36(5): 530-43.

[http://dx.doi.org/10.15537/smj.2015.5.10785] [PMID: 25935172]

[16] Green JG, Vermillion JR, Di Nicoló R, et al. The simplified oral hygiene index. J Am Dent Assoc 1964 Jan; 68(1): 7-13. [http://dx.doi.org/10.14219/jada.archive.1964.0034]

[17] Caneppele TMF, Jeronymo RDI, Di Nicoló R, et al. Di Nicoló, Rebeca, Araújo, Maria Amélia Máximo de, \& Soares, Luís Eduardo Silva. In Vitro assessment of dentin erosion after immersion in acidic beverages: surface profile analysis and energy-dispersive X-ray fluorescence spectrometry study In: Brazilian Dental Journal. 2012; 23: pp. (4)373-8.

[http://dx.doi.org/10.14219/jada.archive.1964.0034]

[18] Al-Jobair AM, Al-Sadhan SA, Al-Faifi AA, Andijani RI, Al-Motlag SK. Medical and dental health status of orphan children in central Saudi Arabia. Saudi Med J 2013; 34(5): 531-6.

[PMID: 23677271]

[19] Alsadhan S. Dental caries prevalence among 12-14 year-old schoolchildren in Riyadh: A 14 year follow-up study of the Oral Health Survey of Saudi Arabia Phase I. Saudi Dent J 2006; 2006: 18.

[20] AlDosari A M, Wyne A H, Akpata ES, Khan N B. Caries prevalence and its relation to water fluoride levels among schoolchildren in Central Province of Saudi Arabia.

[http://dx.doi.org/10.1111/j.1875-595X.2004.tb00299.x]

[21] Ozbek CD, Eser D, Bektas-Kayhan K, Unur M. Comparison of the tooth brushing habits of primary school age children and their parents. J Istanb Univ Fac Dent 2015; 49(1): 33-40.

[http://dx.doi.org/10.17096/jiufd.19356] [PMID: 28955523]

[22] Khare V, Koshy A, Rani P, Srilatha S, Kapse S, Agrawal A. Prevalence of dental caries and treatment needs among the orphan children and adolescents of Udaipur district, Rajasthan, India In: J Contemp Dent Pract. 2012; 1;13: pp. (2)182-7.

[23] Poggio C, Viola M, Mirando M, Chiesa M, Beltrami R, Colombo M. Microhardness of different esthetic restorative materials: Evaluation and comparison after exposure to acidic drink. Dent Res J (Isfahan) 2018; 15(3): 166-72.

[http://dx.doi.org/10.4103/1735-3327.231863] [PMID: 29922334]

\section{(c) 2020 Alsayeh et al.}

This is an open access article distributed under the terms of the Creative Commons Attribution 4.0 International Public License (CC-BY 4.0), a copy of which is available at: https://creativecommons.org/licenses/by/4.0/legalcode. This license permits unrestricted use, distribution, and reproduction in any medium, provided the original author and source are credited. 